\title{
El Psicoanálisis
}

\author{
POR HONORIO F. DELGADO \\ Interno del Hospicio de Insanos \\ (Continúa de la pág. 158 del No 5)
}

CAPITULO IV

\begin{abstract}
-Je suis persuadé que la varite est bin de ce qu'on appelle bon sens, qui n'est qu'un rames d'oplnions, d'habitudes; de conventions: quand nous le verrons, is verite, nous serons tout etonnc de it trouver, et chacun dira: je ne croyais pas que ce lut cela.p
\end{abstract}

Ernegt Rewax. (1)

AS ideas de FReud, a pesar de fundarse sobre una solida base - de observación, han sido recibidas con una desaprobación casi unánime. Al principio no conoció el psicoanálisis sino detracteres: era natural: las nuevas doctrinas chocaban muy directamente contra los prejuicios más arraigados, pues ael psicoanálisis saca a luz lo peor en cada hombrew. (2) Nadie trato de llevar a la práctica las teorías freudiarias, para comprobar su verdad o para demostrar su error; durante diez años se menospreció estas ideas valiosas, por el hecho de que era uno solo el hombre que las sostenía. Cegados por un conservatismo lleno de gazmoñería, come si en la ciencia hubiera algo más moral que la verdad, los psiquiatras olvidaban lo que ya en 1637 dijera DEscartes: "La pluralidad de voces no es una prueba que valga nada para las verdades un poc•

(1) Renan, Letres a Liart, (1842) .Fragments Intimes et Homanesquew, 6. Ed. Paris, p. 197.

(2) Freud, The History of the Psychanalylic Movement, New York, 1916, p. 30. 
difficiles de descubrir, a causa de que es mucho más verosímil què un hombre solo las haya encontrado que todo un pueblon. (1)

Como nuestro propósito no es hacer historia, diremos solamente cuáles han sido las objeciones menos despreciables, por 10 demás muy repetidas, de los críticos-prescimdimos de las de los zoilosdel psicoanálisis. La imprecisión de ałgunos términos, la importancla del factor sexual, la arbitrariedad en la interpretación de los simbolos y el peligro del tratamiento: tales son los puntos cardinales de la crítica antipsicoanalítica.

El hecho de que Freun haya llamado sexuales las manifestaciones de la actividad psicobiologica intantil, que antes habian pasado desapercibidas, pues a nadie se le ocurrí ni hacer una rigurosa investigación catamnésica de la vida de los neurópatas; hasta llegar a las experioncias olvidadas de los primeros años, no existentes en apariencia, ni analizar la conducta de los niños; y si muchos oyerón decir a los niños que en grandes se casarían con su madre y que matarían a su padre si él resultaba un impedimento, creyeron solo que era una cosa sin sentido; el nombre de sexuales a actividades que antes no se llamaba así, decíamos, es lo que ha motivado las críticas más acerbas. "Todo lo que crea un sabio en un hecho-ha dicho Henry PoIncare-, es el lenguaje en el cual lo hà enunciados. (2) Así, pues, la palabra, psicosexual o li bido; que emplea Freud, puede ser rechazada pero quedan los hechos, los hechos irrefragables, con sus vinculaciones causales con la sexualidad madura y con las perturbaciones psicopatológicas.

PierRe Janet, en su. relatorio sobre el psicoanálisis, presentado al Congreso Internacional de Medicina, reunido en Londres, en 1913 (3), dice: "Para nosotros este método ha sido sobre todo un método de construcción simbolica y arbitraria, muestra cómo podrian explicarse las cosas, en el caso en que el origen sexual de las neurosis sería definitivamente admitido; (4) no hay lugar de aplicarlo en tanto que este principio no sea demostrado." (5) Pero, como él mismo lo confiesa, jamás ha hecho el psicoanálisis

(1) Descartes, Discours de la Methode, Edition Lutetia, Paris, p. 33.

(2) Poincare, La valeut de la Science, Paris, 1912, p. 233.

(3) A propósito de esta comunicación, dice Freud lo siguiente: en Paris mismo parece reinar ańn la convicción que cada cosa buena en el pricanálisis solo repite, con pequeñas modíficaciones, las vistas de Janet siendo malo todo lo demás del psicosnálisis. El mismo JaNET hs tenído que soportar en ese Congreso buen número de coTrecciones de ErNEST JoNEs, quien le vituperó por sú falta de conocimiento del asun10.1- Frsud, The History of the Psichanalytic Movement, p. 24.

(4) JANET admite la intervención sexual solo en los tres cuartos de los casos de los neurosis. ( $V$. la cita que sigue.)

(5) Janet, La Psycho-Anabyse, Journal de Psychologie Normale et Pathologique, XI, 1 y 2,1914 , p. 112. 
de un neurópata. No nos imaginamos de qué modo le puede venir la convicción, sino es tratando de verificar los principios que pone en duda.

Los orincipios del psicoanálisis son verdades, por lo menos verdades pragmaticas, (1) que son suficientes en las ciencias aplicados, como son las médicas. Si «verdad y error tienen las mismas fuentes psíquicas" y "sólo el éxito permite separarlos», (2) es una verdad indiscutible el concepto de libido, pues ajustándose a él la conducta del médico, tiene éxito en desterrar el síntoma: y no se arguya que por la sola acción de la sugestión, pues el psice. análisis principalmente se aplica, con éxito frecuente, en los cas os en que todos los otros procedimientos psicoterápicos fracasan, y, sobre todo, porque es el único método que sale fuera de la sugestión, o, como dice ERNEST Jones, (la neutraliza de una manera sistemática». (3) El clasico apotegma: naturam morborum curationes ostendunt, se puede, pues, aplicar, con justicia, al psicoanálisis.

Los mismos argumentos podemos aplicar a la refutación de las objeciones hechas al simbolismo. En defensa de ambos conceptos esta la comprobación de la constancia e igualdad de resultados en manos de diversos observadores. Además, como repara el célebre y ecuánime psicólogo William Mac Dougall, profesor de la Universidad de Oxford, uuna confirmación útil de las operaciones subconscientes de tendencias reveladoras ha sido suministrada por un procedimiento experimental muy simple». (4) Pero a los críticos no seles ha ocurrido hacer una revision de los estudios de asociaciones experiementales de JUNG antes de vociferar en contra del psicoanálisis.

REgis y HESNARD (5), aunque se abstienen de dar una apreciación global del psicoanálisis, son de los que conceptúan, no sél • que es arbitrario el simbolismo libidinoso, sino que la insistencia del analista en las ideas que han sido patógenas puede ser perjudicial para el enfermo, creen que esto puede acentuar más las obssiones, etc.: pero estos señores no se han tomado el trabajo de analizar siquiera sus sueños, que es el primer paso indispensable para el conocimiento del simbolismo: sin conocer no es permitido juzgar. Si REGIS y HESNARD, como todos sus predecesore y secuaces

(1) Las ideas verdaderas son las que podemos verificar. Un proceso indirecto o simplemente virtual de veriflcacion puede ser tan verdadero como un proceso dirpct. y completo.-W. James, Le Pragmatisme, Parls, 1911, p. 185 y 191.

(2) MACH, La Connatssance et l'Erreur, Parls, 1908. p. 124.

(3) JONEs, The Thetapertic Action of Psycho-Analysis, Review of Nenrolos and Psychlatry: $\mathrm{X}, 2,1912, \mathrm{p} .2$.

(4) Mc. Dougall, Psychology: The study of Behaviour, London, 1912. p. 208-9:

(5) Regis et Hesnard, La doctrine de Freud et de son école, 'L'Encéphaler, VIII, 4,5 y 6,1913 . 
en la crítica del psicoanálisis, analizaran 2000 ensueños al año, como lo hace JUNG, entonces si tendrían valor sus juicios, pues hablarian con conocimiento de causa. No hay crítico del psicoanálisis que no lo ignore, por lo menos en su práctica: todos los adversarios que primero lo han estudiado a fondo, teorica y prácticamente, se han convertido en sus ardientes defensores: tales son los casos de Ferenczi, de Bjerre, de Putnam, de Pfister, que a priori juzgaban los postulados freudianos como creaciones artificiales e inverosímiles.

Son raros los enemigos del psicoanálisis que le niegan todo valor; pocos son los que niegan el talento psicológico de su autor. El mismo JANET (1) termina su ataque al psicoanálisis con estas palabras: «Más tarde se olvidarán las generalizaciones exageradas y los simbolismos aventurados que hoy día parecen caracterizar estos estudios y separarlos de los otros trabajos científicos, y no se recordará sino una sola cosa, esto es que el psicoanálisis ha prestado grandes servicios al anánlisis psicologico*. (2)

De una manera general, las nuevas ideas se van imponiendo poco a poco: es así que el profesor Dercum, de Filadelfia, que en 1909 encabezara una cruzada contra el psicoanálisis, en su manual de enfermedades mentales, publicado en 1914, le consagra un capítulo íntegro, admitiendo con pequeñas reservas, la doctrina de los complejos. (3) Asimismo, KRAEPELIN, que moteja al psicoanálisis de "metapsiquiatría», declara en la última edición de su tratado, a propósito de los dementes precoces, que nmuchas expresiones y actos de estos enfermas no son privados de sentido, y que ciertamente las tendencias sexuales juegan en ellos un pape considerablen. (4) Esta opinión se debe, sin duda, a la veríficacion que su discípulo WILHELM PETERS ha hecho de los experimentos de JUNG.

Los más recios ataques al freudanálisis no han conseguido mermar en lo más mínimo el valor de la nueva psiquiatría en tanto que método clínico: está hoy en el consenso de los que conocen el psicoanálisis, aun de los que impugnan la teoría pansexualista, que como técnica es una innovación de la más grande trascenden-

(1) MAEDER, ha hecho ver como se vinculan las doctrinas de Freud y de JANET sobre las neurosis. Según el, lejos de excluirse, se completan mutuamente: siendo el sarácter distíntivo de la de JANET el punto de vista estático y de la de Freud ba concepción dínámica.-V. Maeder, Sur le Movwement Psychanalylique, -Anne Psychologiquer, XVIII, 1912, p. 389-417.

(2) JANeT, La Psycho-Analyse, Journal de Pyychologie Normale et Pathologique, XI, 2, 1914, p. 130.

(3) DEncum, A Cltnical Manual of Mental Diseases, Philadelphia, London, 1914, Part III, p. $351-367$.

(4) Kraepelis, Psychiatrie, 8a. Ed. Leipzig, 1913, T. III, p. 938. 
cia. Este modo de apreciar el psicoanálisis se refleja clara y para i. máticamente en el reciente discurso presidencial de E. W. TAYL en la American Néurological Association: Tratando de las tenden. cias que influirán en la orientación del progreso hacia una com. prensión más profunda de las cuestiones fundamentales concer. nientes a la neurología, dice el ilustre representante de la ciencia americana, que "la significación y el valor permanente de la turba. dora renovación a que está asociado el nombre de FREUD, resice. no en los detalles, ni siquiera en sus conocimientos (accomplish. ments), sino más bien en su método de acercar los hechos a las cuestiones fundamentales». (1)

Es indudable que mañana será un oprobio para los hombres de ciencia de hoy haber menospreciado. cegados por un femenil e infundado sentimiento de honestidad, el más valioso descubrimiento médico de la época. No por estras palabras se crea que pretendemos sostener que el psicoanálisis sea el deus ex machina que resuelve todas las incertidumbres de la psiquiatria: bien sabem que bastante queda por conocer y que muchos de sus principios han de sufrir modificaciones y rectificaciones con el progrese de su práctica, pues ellos son verdades en marcha, no dogmas invariables.

Queremos señalar ahora las dos nuevas escuelas psicoanaliticas segregadas de la de FREUD en virtud de un proceso de secsión gradual. Dos de los más conspicuos discípulos del fundador capitanean las nuevas orientaciones: C. G. JUNC y AlfRed AdLer.

La reforma de Jung consiste, en primer lugar, en la ampliación del concepto de libido. Sostiene el psicoanalísta disidente ue si escierto que desde el punto de vista filogenético «las infinitas y complicadas funciones a las que hoy se debe negar todo carácter sexual fueron originariamente puras derivaciones del impuls general de propagación", (2) no es menos verdaderoque en laconstitución psicológica del individuo la sexualidad no es más que un• de los factores a que anima el libido; entendiendo por tal: kaquella energía que se manifiesta por los procesos vitales, la cual es subjetivamente percibida como aspiración, anhelo y esfuerzo». (3) (A J UNG no desagrada sustituir la palabra libido por la de «interés", que le ha sugerido Claparede.) Durante los primeros años de la

(1) TAxLor, Disease and Symptoms. A plea for a wider Generalization, The Journal of Nervous and Mental Diseasen, 46, 1, 1917, p. 6.

(2) JUNG, Psychology of the Unconscions: $A$ Studes of the Transformations and Symboltswls of the Libido, New York, 1916, p. 144.

(3) Juna, The Theory of Psychoanalysis, Nitw York, 1916, p. 40. 
existencia humana el libido es, según nuestro autor, esencialmente nutritivo; esta es la fase presexual, que dura hasta los 3 c 5 años, en que comienza el libido su diferenciación sexual, siendo sus primeras manifestaciones la formación de los componentes eróticos. que en conjunto forman la llamada por FREUD perversidad polimorfa del niño. Este proceso prepuber es el preparatorio de la actividad propiamente genital del adulto. Después tiene lugar un proceso de desexualizacion, en virtud del cual el libido de la esfera sexual se transfiere a otros usos éticamente superiores, como són los de la adaptación a la realidad cósmica y social: es sublimado en el mejor de los casos, y reprimido en caso desfavorable.

Aunque JUNG admite para las neurosis una perturbación del libido sexual, explica la psicosis, y en particular la demencia precoz, por alteraciones del libido asexual que condiciona la función de lo real.

Según el concepto energético del libido, para que su corriente entre en regresión, esto es, para que el libido se estanque y su nivel suba hasta llenar los canales más antiguos que recorriera en la infancia del sujeto, es menester que haya una causa que disminuya - imposibilite su flujo, esto es, una dificultad en la tarea de la vida: no pudiendo el libido satisfacer las demandas de la realidad actual, fracasado así el esfuerzo de adaptación, la indolencia crea un nuevo estado de cosas activando el mundo de las imágenes del pasado, reviviendo los motivos a que se adhería entonces el libido; esto significa que el individuo se adapta conforme a su estructura mental primitiva. De tal modo explica que las causas patógenas radiquen en el momento del conflicto actual y que el contenido morboso esté formado por las reminiscencias.

JUNG y MAEDER están contestes para sostener que los símbolos del libido no representan exclusivamente los problemas de la sexualidad, sino que, siendo polivalentes, representan tanto productos de regresión como esfuerzos de orientación finalista. Desde este punto de vista, los símbolos sexuales no son sino medios de expresión psicologica de la subconsciencia.

Los sueños resultan ser, no meramente la expresión de deseos reprimidos, sino también la representación de la situación actual del individuo en la vida, y los planes para el porvenir, por medio de símbolos sexuales. "La interpretación de FREUD-dice MAEDER, de acuerdo con JunG,-la considero como la etapa preliminar de là interpretacion actual. Es, por decirlo así, el material pintoresco que debe ser traducido al intelectual: da el de donde del símbolo, 
mas no el adonde....; da lo retrospectivo, mas no lo prospec. tivon. (1)

A pesar de todas estas divergencias, la Nueva escuela de Zurich (así se llama el grupo de psicoanalistas que siguen, en Zurich, las doctrinas de JUNG) apenas ha modificado su técnica psicoterá. pica, agregando solamente consejos y apoyo moral para que el individuo afronte con ventaja los problemas de la vida. Si la sexualidad es simplemente el lenguaje de la subconsciencia, nos preguntamos, cómo es que la sola acción sobre ella puede bastar a roducir la readaptación del sujeto. Usando en la práctica terapéutica e] psicoanálisis freudiano, JuNG confiesa la inanidad de sus innevaciones destructivas: resultan ser meras atenuaciones de forma. Son, sí, de inapreciable trascendencia, si se considera las innovacienes constructivas, pues sin desmedrar lo adquirido, lo completan. En su comunicaciór. al Congreso Internacional de Medicina, de Londres (1913), JUNG ha intentado justificar el uso del psiceanájisis sexual de la siguiente manera: "Tenemos que extirpar las fantasías sexuales porque la energía que necesita el paciente para su salud, o sea para su adaptación, está adherida a ellas. Por medie del psicoanálisis se establece de nuevo la conexión entre la conciencia y el libido de la subconsciencia. De este modo se restaura el libido subconsciente al comando de la intención consciente. Solamente en esta vía puede la energía disgregada llegar a ser nuevamente aplicable a la realización delas tareas necesarias de la vida).

De mayor entidad es la divergencia entre las ideas de Alfre ADLER y las de su maestro, aunque en el fondo la innovación consiste--por lo menos en algunos puntos-en una hábil sustitución de valores o acaso sólo de nombres.

Partiendo de la premisa de que la inferioridad constitucienal de un órgano condiciona una mayor actividad funcional, gracias a una repercusión hiprecompensadora, de los centros nerviosos y de la esfera mental cuya atención es solicitada por el órgano y al cual se esfuerza en proteger, ADLER concluye "que el conjunt de ferómenos de la inferioridad orgánica se refleja en la psiquis en tal forma que su estructura total sufre una impresión peculiar. La estructura psíquica así obtenida llega a ser la base para neurosis y psicosis». (3)

(1) Maeder, The Dream Problem, New York, 1916, p. 13.

(2) Jung, On Psychoanalysis, Collected Papcrs, p. 23.5 . York, 1917, p. 23. 
Según AdLer, el individuo, desde la más tierna infancia, se hace cargo de sus deficiencias corporales, o de cualquera índole, lo cual da lugar a que en él nazca y se desarrolle un sentimiento de incapacidad, que trata de compensar con la eficiencia de su carácter, al cual pretende orientar y robustecer según un plan que determina para el futuro, en vista de conseguir desarrollar en sí un sentimiento compensador de superioridad personal. El sujeto normal triunfa continuamente sujetando su plań vital dentro de los límites que impone la adaptación a la realidad exterior. El neurópata, por el contrario, falla en la adaptación a la realidad y actúa "bajo la norma de un plan de vida ficticio". (1) En otros términos, en la niñez la actividad psicologica del individuo se orienta en un sentido exclusivamente teleológico, lo cual da lugar a que el individuo se crée una personalidad subjetiva a su antojo: -lo que sostiene al hombre y le guía a cada paso en su camino es su des eo de suprema superioridad, su idea de semejanza con dios, su fe en su fuerza sobrenatural». (2)

La neurosis es el refugio en donde la personalidad que ha roto la harmonía con el mundo exterior continúa cultivando la mentira que es esencial a su constitución. La sintomatología es lo ostensible de la protesta viril del ego ilusorio que lucha con la realidad por afirmarse y conseguir, a precio de la desadaptación, la propia seguridad.

Respecto a los estados psicósicos, en la paranoia y en la demencia precoz tenemos la acentucaión extrema de la protesta y de la búsqueda de seguridad, respectivamente, en la prosecusión de la línea directriz de la existencia hacia el poder de dominio: en efecto, la conducta del paranoiaco es el tipo caricatural de la defensa de una personalidad hiperbólica. Por otra parte, el demente precoz es el arquetipo de la subjetivización absoluta: el sujeto se aísla por completo del exterior, prescinde de él para refugiarse en el mundo ideal autogenerado, donde no se encuentran resistencias que combatir ni deficieacias personales que sufrir.

Para la escuela adleriana, llamada de la Psicologia Individual, la significación de la sexualidad se reduce a la de una "manera de hablarn, a la de simbolos de expresión de las manifestaciones reactivas del ego q' se afirma y protesta. El complejo de Edipo es asimismo una actitud psicológica que significa simplemente el afán de dominar a la madre y de hallar seguridad identificándose con

(1) ADLER, Ueber den nervoesen Chatakter, Wiesbaden, 1912, p. 36.

(2) ADLER, DLe Indivtdualpsychologie, thre Voraussetsungen und Ergebntose, -Scientias, XVI, XXXVI, 1914, P. 80. 
el padre, dada la inferioridad corporal del niño y las limitaciones que ella le impone.

Como el freudanálisis, la psicología individual, en su tarea terapéutica,se remonta, por análisis, hasta la infancia, donde está la semilla del sistema de seguridad, y presentándolo claramente a través del simbolismo sexual, a la crítica del sujeto, consigue el médico que el paciente abandone la línea vital que lo ha conducido a la enfermedad, a cambio de otro plan que concuerde con sus ap ti. tudes efectivas y con la realidad de la vida.

Como se vé, en la doctrina de ADLER figuran, como en la de FREUD, dos sistemas en perpetuo duelo, la vanidad y el sentid. de la realidad. La primera no sustituye totalmente al libido, pues ADLER no deja de aceptar el factor sexual como importante en el dinamismo de la psiquis, sólo que no lo considera exclusivo. En lo fundamental no hay propiamente contradiccion entre las teorias de ambos autores: FREUD postula que el contenido profunde de los trastornos psíquicos son los deseos infantiles reprimidos: ADLER considera que lo pałológico es que esos deseos infantiles tiendan 2 su satisfacción por medio de creaciones ficticias a causa de una incapacidad de compensación de alguna inferioridad por medie de adaptaciones concordes con la realidad.

En lo substancial de esto hay dos conceptos nuevos q' pueden agregarse a las conquistas freudianas, tales son: el de la inferioridad orgánica como punto de arranque o estímulo para el desee, y el del fin ilusorio para conseguir la seguridad contra tal inferieridad. La experiencia del porvenir se encargará deseñalar los just Jímites de los factores descubiertos. Quizá el único pecado de ADLER es haber generalizado de manera demasiado absoluta. De tedos modos, su contribución a la psicología del individuo es muy apreciable y útil.

(Continuaré)

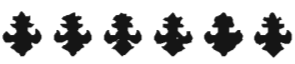

